\title{
EMPREGO DE FUBÁ DE MELHOR QUALIDADE PROTÉICA EM FARINHAS MISTAS PARA PRODUÇÃO DE BISCOITOS ${ }^{1}$
}

\author{
Fátima F. P. GUILHERME², Lieselotte JOKL ${ }^{3, *}$
}

\section{RESUMO}

Farinhas mistas (FM) à base de farinha de trigo com substituição parcial por isolado protéico de soja, soro de leite em pó e três tipos de fubá (mimoso ou de cultivares BR451 e BR2121) foram preparadas para melhorar a qualidade protéica da farinha de trigo. As características sensoriais e químicas dos biscoitos foram avaliadas, e o valor protéico em potencial foi calculado. Os resultados foram comparados com os da farinha de trigo ou seu biscoito (controles). Os teores em macronutrientes nas FM e nos biscoitos foram superiores aos dos respectivos controles, com exceção de carboidratos. Apenas na aparência o biscoito com FM BR2121 foi estatisticamente inferior à daquele com FM mimoso, sendo semelhantes ao controle e aos outros biscoitos na textura e no sabor. O biscoito com FM mimoso teve a maior aceitação. O valor calórico médio dos biscoitos foi de $436 \mathrm{kcal}$. A qualidade protéica dos biscoitos com as FM - lisina e treonina como aminoácidos limitantes e C-PER em torno de 2 - foi superior a do controle. O custo (preço/kg) dos biscoitos assados com as FM foi superior ao do biscoito controle, devido ao custo da FM ter sido cerca do dobro da farinha de trigo pura e de se necessitar maiores quantidades de ingredientes na formulação.

Palavras-chave: biscoitos; caracterização; farinha de trigo, farinhas mistas; milho de qualidade protéica; valor protéico em potencial.

\section{SUMMARY}

USE OF QUALITY-PROTEIN MAIZE IN FLOUR BLENDS AND IN THE PRODUCTION OF COOKIES. Flour blends (FB) based on wheat flour with partial substitution for isolated soy protein, powdered whey and three corn flour types (common or cultivar BR451 and BR2121) were prepared to improve the protein quality of wheat flour. The sensory and chemical characteristics of the cookies were evaluated and the potential proteic value was calculated. The results were compared with the wheat flour or its cookie (controls). Macronutrients levels in FB and cookies were superior than those in the respective controls, except for carbohydrates. Only in the appearance the cookie made with FB BR2121 was statistically inferior to the one with common corn FB, being similar to the control and other cookies in texture and flavor. The cookie with common corn FB had the highest acceptance. Cookies mean caloric value was 436kcal. The proteic quality of the FB cookies - lysine and threonine as limiting essential amino acids and C-PER about 2 - was superior than the control. The baked FB cookies cost (price $/ \mathrm{kg}$ ) was superior than the control, because the FB cost was about the double of the wheat flour and also the necessity to use higher quantities of ingredients in the formulation.

Keywords: characterization; cookie; flour blend; potential proteic value; quality-protein maize; wheat flour.

\section{1 - INTRODUÇÃO}

O Brasil é um país com grande extensão territorial e cinco regiões caracterizadas por hábitos, recursos naturais e condições sócio-econômicas diversificados. No entanto, apresentam uma realidade em comum, embora variável em sua amplitude: o contingente de pessoas que vive em situação de pobreza. A alimentação da maior parte desta população se baseia em alimentos como arroz, fubá, farinha de mandioca e açúcar. Estes produtos representam apenas fontes calóricas e não são suficientes para fornecer os outros macronutrientes e alguns micronutrientes essenciais às funções do organismo humano e à realização das atividades diárias. Como os recursos disponiveis para a obtenção de uma alimentação saudável são escassos

1. Recebido para publicação em 05/05/2003. Aceito para publicação em 31/05/2005 (001121. Dissertação de Mestrado em Ciência de Alimentos da Faculdade de Farmácia da Universidade Federal de Minas Gerais, do $1^{\circ}$ autor.

2. Vigilância de Alimentos da Secretaria de Estado da Saúde de Minas Gerais.

3. Faculdade de Farmácia da Universidade Federal de Minas Gerais, $R$. Gal. Andrade Neves, 76/4 - CEP 30430-070 Belo Horizonte, MG. E-mail: lisejokl@dedalus.lcc.ufmg.br

* A quem a correspondência deve ser enviada. para esta parcela da população, é importante desenvolver alimentos protéicos de bom valor nutritivo e preço compativel com o nivel de renda da população.

Em regiões subdesenvolvidas, um quinto da população tem menos de cinco anos de idade, sendo que mais da terça parte sofre de enfermidades ou males que prejudicam sua capacidade fisica e mental e que são causados ou agravados pela desnutrição protéicocalórica. Sendo atendidas a tempo, com alimentação adequada para recompor e manter suas necessidades energéticas e protéicas, a evolução destas deficiências poderá ser revertida ou, pelo menos, interrompida. Nutricionalmente, as farinhas mistas de boa qualidade protéica podem ser adicionadas para fortificar os biscoitos, tornando sua proteína mais balanceada sem, no entanto, alterar muito a qualidade tecnológica.

A idéia de produção de farinhas compostas no campo de panificação e confeitaria não é nova [10, 11]. A viabilidade técnica e econômica do uso de farinhas mistas em alimentos também já foi amplamente demonstrada e empregada na indústria. No Brasil, alguns programas de produção de alimentos formulados têm surgido em que se procura substituir a proteína de origem animal da dieta - ou reduzir a quantidade de sua fonte - por fontes de origem vegetal, uma vez que estas apresentam custos mais baixos. Os derivados protéicos da soja e do milho têm sido muito usados na suplementação ou em substituição parcial da farinha de tri- 
go, para a obtenção de produtos como pão, biscoito e macarrão.

Ao formular a farinha mista para uso em panificação e confeitaria, deve-se considerar alguns aspectos para que seja viável de aplicação. Dentre eles consideram-se: as propriedades reológicas da massa e as características físicas, sensoriais e nutricionais das matérias-primas empregadas na formulação. Além disto, os produtos devem apresentar valor nutricional pelo menos igual ao daqueles com farinha de trigo pura e o custo final das misturas deve ser igual ou inferior ao preço final da farinha de trigo pura [12, 14].

O emprego de milhos de melhor qualidade protéica (QPM - quality protein maize) - desenvolvidos a partir do milho Opaco-2 - na substituição parcial da farinha de trigo foi pesquisado colaborativamente entre os Centros Nacional de Pesquisa de Milho e Sorgo e o de Tecnologia Agroindustrial de Alimentos, ambos pertencentes à Empresa Brasileira de Pesquisa Agropecuária EMBRAPA. Foram avaliadas as características tecnológicas de diversos cultivares QPM direcionadas, principalmente, para a panificação, obtendo-se resultados promissores [25]. Mas também outras fontes protéicas, como soro de leite e derivados de soja, vêm sendo pesquisadas na formulação de misturas panificáveis [23, 27], com igual sucesso.

Os objetivos desta pesquisa foram o desenvolvimento de farinhas mistas, compostas basicamente de farinhas de trigo e fubá - mimoso ou QPM (cultivares BR451 e BR2121) assim como um derivado de soja e o soro de leite em pó, e avaliar sua viabilidade na produção de biscoitos. Para isto foi necessário: a - determinar a composição centesimal das matérias-primas e adequar uma formulação com qualidade protéica aceitável pelo escore químico e com base na aceitação dos biscoitos experimentais, por meio da avaliação sensorial; b - determinar a composição centesimal das farinhas mistas; avaliar as características sensoriais e químicas, o potencial nutricional e os custos dos biscoitos.

\section{2 - MATERIAL E MÉTODOS}

\section{1 - Material}

Amostras de várias fontes de proteínas foram conseguidas por doação: farinha de trigo; proteína texturizada de soja - PTS, isolado protéico de soja IPS e fubá mimoso comum; fubás QPM (milho de qualidade protéica) branco - BR451 e amarelo - BR2121 degerminados (EMBRAPA - Sete Lagoas/MG) e soro de leite em pó - SLP. Estes ingredientes básicos foram armazenados em suas embalagens originais e guardados em caixas de polietileno rígido hermeticamente fechadas ou no freezer até o momento de análise e preparo das farinhas mistas ou biscoitos. Outros ingredientes utilizados na elaboração dos biscoitos: açúcar refinado, fermento em pó e margarina com sal $180 \%$ de lipides) foram adquiridos em supermercado.

\section{2 - Métodos}

\subsection{1 - Composição centesimal da matéria-pri- ma e das farinhas mistas}

Os seguintes constituintes foram determinados em triplicata:

a - umidade, proteína bruta, lipides e cinzas [4]. Foram utilizados os seguintes fatores de conversão de teores de nitrogênio para proteína: 5,70 para a farinha de trigo; 5,71 para os PTS e IPS; 6,38 para o SLP e 6,25 para os fubás [15];

b - fibra bruta - pelo método gravimétrico de SharrerKürschner [8];

c - carboidratos - por diferença, considerando-se que cada repetição representaria uma amostra do produto [8, 24].

\subsection{2 - Preparo das farinhas mistas}

Com base nos teores de nitrogênio dosados nas diferentes fontes protéicas e nas respectivas composições teóricas em aminoácidos essenciais, foram preparadas diversas combinações de modo a se obter um escore químico próximo ou igual a 1 [26], principalmente em relação aos aminoácidos lisina e triptofano.

As diversas matérias-primas foram tamisadas em tamis de 20mesh e misturadas em masseira (Moema; $5 \mathrm{~kg}, 3$ velocidades) por $15 \mathrm{~min}$. Cada farinha mista (FM) foi avaliada por meio da análise sensorial dos biscoitos elaborados com a mesma, procurando-se manter sempre as características do produto final. Uma vez estabelecida a combinação ideal, as FM selecionadas foram acondicionadas em sacos plásticos de polietileno de alta densidade, selados, identificados e guardados em refrigerador a $15^{\circ} \mathrm{C}$, até o momento do uso.

\subsection{3 - Escore químico teórico das farinhas mistas}

O escore químico da fonte protéica é dado pela razão entre os teores de aminoácidos essenciais da proteína teste e os de uma proteína de referência [17, 26]. As composições em aminoácidos essenciais (mg/ g N) das fontes protéicas foram compiladas da literatura pertinente $[10,15,16,25]$. Estas concentrações foram ajustadas aos teores de nitrogênio das respectivas matérias-primas - obtidos por análise - sendo expressas em $\mathrm{mg} / \mathrm{g} \mathrm{N}$. O escore químico das FM foi calculado a partir da composição em aminoácidos essenciais das respectivas fontes protéicas, levando em consideração as diferentes proporções nas formulações avaliadas [26].

\subsection{4 - Preparo dos biscoitos}

A formulação básica dos biscoitos controle (contendo apenas farinha de trigo) foi adaptada da considerada padrão e descrita no método 10-50 D [1]. Tanto os biscoitos testes como os definitivos foram preparados da mesma forma que o controle, substituindo-se apenas a farinha de trigo pelas respectivas FM. Os biscoitos 
foram do tipo não-fermentado, semidoce duro e formado por rolo [12].

A massa foi processada na masseira a baixa velocidade. Misturaram-se, inicialmente, a margarina e o açúcar por um período de 3 min. A seguir, adicionaramse uma parte de água destilada e o fermento químico. Após este preparo, acrescentaram-se farinha de trigo ou FM e água, esta em quantidade suficiente para tornar a massa homogênea. A massa foi misturada em baixa velocidade por cerca de 3 min e depois pesada e dividida em porções menores. Foi estendida por sistema de dois rolos e a moldagem dos biscoitos foi feita com auxílio de forma circular. Os biscoitos foram assados a $204^{\circ} \mathrm{C}$, por $19 \mathrm{~min}$, em forno elétrico (Layr Cristal, $1.75 ; 40 \mathrm{~cm} \times 60 \mathrm{~cm}, \mathrm{t}=0$ a $300^{\circ} \mathrm{C}$; acoplado a um controlador de temperatura Fornax 1000). Após o assamento, foram resfriados à temperatura ambiente e acondicionados em sacos pequenos de polipropileno. Estes foram guardados em sacos de polietileno de alta densidade e conservados em caixas hermeticamente fechadas, à temperatura ambiente, até se realizarem as análises químicas e sensoriais. Na etapa dos biscoitos teste, preparava-se cerca de $600 \mathrm{~g}$ de massa, enquanto na dos definitivos, foram cerca de $2 \mathrm{~kg}$.

\subsection{5 - Avaliação sensorial dos biscoitos}

Os provadores, inicialmente não-treinados, foram selecionados em função da disponibilidade e interesse em participar do teste, tornando-se treinados com a evolução da pesquisa. O teste básico empregado foi o da aceitação, usando-se uma escala hedônica - 1 = desgostei muito a 7 = gostei muito [30]. Os atributos avaliados foram aparência; textura e sabor.

Definidas as melhores formulações, foi realizada nova avaliação sensorial empregando o método de comparação múltipla [6] e incluindo o biscoito com apenas farinha de trigo, identificado como padrão. Com a participação de provadores treinados, foi usada a escala básica de discriminação seguida por uma de medida da magnitude da diferença entre as amostras testes em relação ao padrão para avaliar os atributos aparência; textura e sabor. Além deste, foi também usado o de ordenação [30] - segundo a preferência geral do provador pelos biscoitos contendo as FM, dada em ordem decrescente.

Em todas as avaliações as amostras de cada tipo de biscoito foram tomadas aleatoriamente, codificadas e ordenadas conforme o tipo de teste aplicado e distribuídas em um prato plástico. Eram apresentadas aos provadores localizados em seções separadas numa mesa grande, em uma sala com iluminação uniforme e à temperatura ambiente.

\subsection{6 - Composição centesimal dos biscoitos}

A composição centesimal dos biscoitos foi determinada nas formulações adequadas de biscoito quanto aos aspectos tecnológico, sensorial e escore químico melhorado. Amostras de cada produto, selecionadas aleatoriamente, foram pré-secas de modo controlado em estufa de circulação forçada de ar, a $60^{\circ} \mathrm{C}$ por $16 \mathrm{~h}$; procedendo-se, em seguida, ao cálculo da perda de umidade nesta primeira etapa [9]. Posteriormente, as amostras foram trituradas e peneiradas em tamis de 35 a 40mesh, homogeneizadas e guardadas em recipientes hermeticamente fechados, até a realização das análises dos nutrientes.

As dosagens subseqüentes de umidade, proteína bruta ( $\mathrm{N}$ x 5,70 para o biscoito com farinha de trigo e $\mathrm{N} \times 6,25$ para os contendo as FM), lipides, cinzas e carboidratos foram idênticas às descritas no item 2.2.1, com exceção para o cálculo final da umidade (somatória das duas etapas) e a dosagem de fibra que, no caso do biscoito final, foi o da fibra alimentar e suas frações insolúvel e solúvel, segundo o método enzimo-gravimétrico [3].

\subsection{7 - Qualidade nutricional dos biscoitos}

Como parâmetros nutricionais dos biscoitos escolheram-se alguns que poderiam ser obtidos por cálculo, dando-se ênfase àqueles baseados na energia e no valor nutritivo da proteína. O primeiro - valor calórico baseia-se na composição centesimal do produto, resultante da somatória das multiplicações dos teores de macronutrientes contidos nos biscoitos pelos fatores de Atwater, a saber: $4 \mathrm{kcal} / \mathrm{g}$ de carboidrato ou proteína e $9 \mathrm{kcal} / \mathrm{g}$ de lipide. O segundo - valor nutritivo em potencial da proteína - foi caracterizado pelos seguintes índices:

a - escore químico corrigido [26, 29] ou PDCAAS (protein digestibility-corrected amino acid scoring) [17]: foi calculado tomando-se as composições em aminoácidos essenciais (mg/g N) obtidas no item 2.2.3 para as FM definitivas, que foram idênticas às dos biscoitos. Os escores químicos foram multiplicados pelas digestibilidades in vitro da proteína - $80 \%$ para os de farinha de trigo e $78 \%$ para os contendo as FM - determinadas para biscoitos assados e semelhantes aos aqui estudados [19];

b - C-PER (calculated protein efficiency ratio) [6]: foi calculado tomando-se por base a composição em aminoácidos essenciais (g/16g N) obtida no item 2.2.3 para os diversos biscoitos [18]. Empregaramse para os biscoitos os mesmos valores de digestibilidade [19].

\subsection{8 - Custo dos produtos finais}

O custo dos biscoitos foi calculado a partir das quantidades dos ingredientes utilizados nas diversas formulações necessários para produzir $1 \mathrm{~kg}$ do produto assado. Os preços $/ \mathrm{kg}$ destes ingredientes foram obtidos no mercado atacadista ou consulta ao produtor, levantados no período de 28 a 31 de outubro de 2002. Considerouse o custo do fubá de QPM igual ao do fubá mimoso.

\section{3 - Análise estatística}

A comparação das médias de cada parâmetro da composição centesimal (3 ou 4 tratamentos, 3 repetições), 
foi realizada pelo teste de Tukey a $5 \%$ de probabilidade [28]. Cada atributo sensorial - aparência, textura e sabor - foi avaliado pelo:

a - teste de aceitação [6]: aplicado aos biscoitos e usando os valores assinalados pelos provadores na escala hedônica. As médias foram comparadas pelo teste de Tukey, a 5\% de probabilidade [28];

b - método de comparação múltipla [6, 30]: aplicado aos biscoitos finais em relação ao padrão, em que os resultados foram convertidos em escores conforme o esquema apresentado a seguir:

$\begin{array}{llr}\text { Classificação da amostra } & \text { Teste } & \text { Escore } \\ \text { Melhor que o padrão } & \text { Extrema } & 9 \\ & \text { Grande } & 8 \\ & \text { Moderada } & 7 \\ & \text { Pequena } & 6 \\ \text { Igual ao padrão } & \text { Nenhuma } & 5 \\ \text { Pior que o padrão } & \text { Pequena } & 4 \\ & \text { Moderada } & 3 \\ & \text { Grande } & 2 \\ & \text { Extrema } & 1\end{array}$

As médias foram comparadas pelo teste de Tukey, a $5 \%$ de probabilidade, em que cada atributo tinha 3 tratamentos e 21 provadores;

c - teste de ordenação da preferência geral [30] pelo provador, por ordem decrescente dos 3 tratamentos, e teve a participação de 19 provadores. À seqüência foram atribuídos os seguintes pesos: $3>2>1$. As somatórias dos pesos relativos a cada tratamento foram submetidas ao teste de Friedman e a comprovação foi feita pelo teste de comparação múltipla [5].

\section{3 - RESULTADOS E DISCUSSÃO}

\section{1 - Análise das matérias-primas}

Os resultados da composição centesimal das matérias-primas são apresentados na Tabela 1. O teor de fibra bruta foi determinado, em vez do teor de fibra alimentar, para efeito de comparação com dados da literatura.

De modo geral, os teores de nutrientes determinados nas diversas matérias-primas analisadas encontram-se próximos aos dados tabelados na literatura [10, $13,23,25]$. Como os resultados de umidade para os fubás foram estatisticamente diferentes entre si, calcularam-se os valores dos nutrientes na base seca, para efeito de comparação. Todavia, constatou-se que não houve alteração na resposta estatística para estes compostos. Observou-se que o teor de proteína do fubá mimoso foi um pouco superior ao das cultivares BR. Entretanto, isto não compromete a qualidade protéica dos fubás QPM, visto que a mesma se baseia no fato dos teores de lisina e triptofano serem superiores aos valores tabelados para os do fubá mimoso [25], embora em percentuais variáveis.
TABELA 1 - Composição centesimal das matérias-primas

\begin{tabular}{|c|c|c|c|c|c|c|c|}
\hline \multirow{3}{*}{$\begin{array}{l}\text { Nutriente } \\
(\mathrm{g} / 100 \mathrm{~g})\end{array}$} & \multirow{3}{*}{ FT } & \multirow{3}{*}{ SLP } & \multicolumn{4}{|c|}{ Matéria-prima $^{\top}$} & \\
\hline & & & \multirow{2}{*}{ PTS } & \multirow{2}{*}{ IPS } & \multicolumn{3}{|c|}{ Fubá $^{2}$} \\
\hline & & & & & Mimoso & BR451 & BR2121 \\
\hline Umidade & 13,09 & 3,65 & 6,67 & 7,33 & $8,98 \mathrm{c}$ & $12,23 \mathrm{a}$ & $11,39 \mathrm{~b}$ \\
\hline Proteína bruta ${ }^{3}$ & 9,71 & 12,08 & 48,36 & 80,59 & $8,03 \mathrm{a}$ & $7,25 \mathrm{~b}$ & $7,19 \mathrm{~b}$ \\
\hline Lípides & 0,20 & 1,02 & 0,77 & 0,12 & $0,19 \mathrm{c}$ & $0,89 \mathrm{~b}$ & $1,25 a$ \\
\hline Cinzas & 0,68 & 7,89 & 5,89 & 3,69 & $0,37 \mathrm{c}$ & $0,50 \mathrm{~b}$ & $0,71 \mathrm{a}$ \\
\hline Fibra bruta & 0,49 & - & 2,66 & - & $0,76 \mathrm{c}$ & $1,18 \mathrm{a}$ & $0,97 \mathrm{~b}$ \\
\hline Carboidratos $^{4}$ & 75,83 & 75,36 & 35,69 & 8,27 & $81,67 \mathrm{a}$ & $77,95 \mathrm{~b}$ & $78,49 \mathrm{~b}$ \\
\hline Nitrogênio & 1,70 & 1,89 & 8,47 & 14,11 & $1,29 a$ & $1,16 \mathrm{~b}$ & $1,15 b$ \\
\hline
\end{tabular}

$1-\mathrm{FT}=$ farinha de trigo; SLP = soro de leite em pó; PTS = proteina texturizada de soja; IPS = isolado protéico de soja; BR451 = fubá de milho branco; BR2121 = fubá de milho amarelo.

2 - Médias seguidas pela mesma letra, na respectiva linha, não apresentam diferenças significativas entre si, a $5 \%$ de probabilidade, pelo teste de Tukey.

3 - Fatores de conversão de nitrogênio: $\mathrm{FT}=5,70$; $\mathrm{SLP}=6,38$; PTS, IPS $=5,71$; fubás

4 - Teor calculado por diferença.

\section{2 - Desenvolvimento das formulações adequadas}

As formulações de farinha mista foram preparadas de modo a conterem $25 \%$ de fubá mimoso ou das cultivares $\mathrm{BR}, 5 \%$ de SLP, alterando-se as proporções de PTS (15 ou 25\%) ou de IPS (10, 15, 20 ou 25\%) e sendo complementadas com as quantidades adequadas de farinha de trigo. Os escores químicos destas farinhas variaram de 0,75 a 0,94 para a lisina. É importante ressaltar que, dos aminoácidos essenciais mais deficientes na farinha de trigo - lisina, treonina, triptofano e leucina, com escores correspondendo, respectivamente, a 0,29;0,64;0,78 e 0,85 - praticamente, apenas o primeiro continuou limitante nas FM. Os resultados obtidos para os atributos aparência e sabor apresentaram sempre as melhores médias - próximas ao máximo da escala hedônica - embora aquelas atribuídas à textura refletissem o fato dos biscoitos não serem do agrado dos provadores. Do ponto de vista sensorial, biscoitos produzidos com até $10 \%$ de derivado de soja são considerados bons, semelhantes ao padrão (apenas com farinha de trigo), com boa textura e sabor. Além deste limite de substituição, já se começava a notar um pronunciado beany flavor [12] - sabor desagradável característico da soja. Este fato poderia ter influenciado na avaliação feita pelos provadores, pois se supõe que o sabor da soja tenha mascarado o de milho nos biscoitos com maior teor de derivados da soja.

Diante dos resultados obtidos, decidiu-se adotar a seguinte formulação $-60 \%$ de farinha de trigo $+10 \%$ de IPS $+25 \%$ de fubá $+5 \%$ de SLP - apesar da redução nos respectivos escores químicos relativos à lisina $(0,76$; 0,80 e 0,80, respectivamente para as FM com os fubás mimoso, BR451 e BR2121). Estes, no entanto, eram o dobro daquele apresentado para a farinha de trigo pura - 0,36 (lisina), acrescida de mais dois aminoácidos limitantes - treonina $(0,80)$ e triptofano $(0,98)$. Assim, a substituição parcial de farinha de trigo pelas outras fontes protéicas melhorou substancialmente sua qualidade nutricional.

$\mathrm{Na}$ avaliação sensorial pelo teste de aceitação, observou-se que as médias dos valores hedônicos atribuídos pelos provadores - de "gostei ligeiramente" (5) a 
"gostei" (6), tanto para a aparência dos três tipos de biscoitos, quanto para o sabor, daqueles contendo os fubás mimoso e BR451 - não diferiram entre si. Entretanto, o sabor do biscoito com o fubá BR2121 foi avaliado entre "gostei e gostei muito". As médias atribuídas à textura continuaram baixas para os biscoitos contendo os fubás mimoso e BR451. Porém, aqueles contendo a FM BR2121 quase alcançaram o valor máximo.

\section{3 - Composição centesimal das farinhas mistas}

Uma vez definida a formulação das farinhas mistas que proporcionou a melhor aceitação sensorial dos biscoitos, foi realizada a análise comparativa da composição centesimal entre a farinha de trigo e as farinhas mistas contendo as diversas fontes protéicas. Os resultados obtidos na base seca são apresentados na Tabela 2.

TABELA 2. Composição centesimal das farinhas de trigo e mistas

\begin{tabular}{lcccc}
\hline \multirow{2}{*}{$\begin{array}{c}\text { Nutriente } \\
\text { (g/100g matéria seca) }\end{array}$} & Farinha de & \multicolumn{2}{c}{ Farinha mista contendo fubá ${ }^{1}$} \\
\cline { 3 - 5 } & trigo $^{1}$ & mimoso & BR451 & BR2121 \\
\hline Proteína bruta $^{2}$ & $11,18 \mathrm{~d}$ & $16,45 \mathrm{c}$ & $22,79 \mathrm{a}$ & $20,32 \mathrm{~b}$ \\
Lípides & $0,23 \mathrm{~b}$ & $0,16 \mathrm{~b}$ & $1,22 \mathrm{a}$ & $1,32 \mathrm{a}$ \\
Cinzas & $0,79 \mathrm{~b}$ & $1,36 \mathrm{a}$ & $1,30 \mathrm{a}$ & $1,37 \mathrm{a}$ \\
Fibra bruta & $0,57 \mathrm{a}$ & $0,06 \mathrm{~b}$ & $0,44 \mathrm{a}$ & $0,11 \mathrm{~b}$ \\
Carboidratos $^{3}$ & $87,23 \mathrm{a}$ & $81,97 \mathrm{~b}$ & $74,25 \mathrm{~d}$ & $76,88 \mathrm{c}$ \\
Nitrogênio & $1,96 \mathrm{~d}$ & $2,63 \mathrm{c}$ & $3,65 \mathrm{a}$ & $3,25 \mathrm{~b}$ \\
\hline
\end{tabular}

1 - Teores de umidade $(\mathrm{g} / 100 \mathrm{~g})$ : farinha de trigo $=13,09 \mathrm{a}$; fubá mimoso $=11,36 \mathrm{c}$ fubá BR451 = 11,89b; fubá BR2121 = 11,83b. Médias seguidas pela mesma letra na respectiva linha, não apresentam diferenças significativas entre si, a $5 \%$ de probabilidade, pelo teste de Tukey.

2 - Fatores de conversão de nitrogênio: farinha de trigo $=5,70$; fubás $=6,25$. 3 - Teores calculados por diferença

Comparando-se os teores dos nutrientes das farinhas mistas com aqueles da farinha de trigo, constatou-se que, de modo geral, são superiores, contribuindo não só com a proteína, mas também com os outros nutrientes (lipides e cinzas). O teor de fibra bruta foi superior na farinha de trigo, uma vez que no preparo das FM foram empregadas matérias-primas com baixo ou nenhum teor de fibra.

Os teores de umidade (g/100g) determinados para as farinhas de trigo $(13,09)$ e as mistas à base dos fubás mimoso $(11,36)$, BR451 $(11,89)$ e BR2121 $(11,83)$ estão de acordo com os valores permitidos pela legislação de farinhas - máximo 14,0g/100 g [7].

\section{4 - Avaliação dos biscoitos}

Uma vez comprovada a adequação das farinhas mistas contendo os fubás de milho QPM, os biscoitos foram preparados (Tabela 3) e caracterizados quanto aos atributos sensoriais, à composição centesimal e ao valor nutritivo em potencial da proteína. Ao mesmo tempo, estes biscoitos foram comparados com aqueles preparados com farinha mista contendo fubá mimoso ou com apenas farinha de trigo (controle ou padrão).
TABELA 3 - Formulações dos biscoitos

\begin{tabular}{lcccccccc}
\hline & \multicolumn{7}{c}{ Biscoito à base de } \\
\cline { 2 - 9 } Ingrediente & \multicolumn{1}{c}{ Farinha trigo } & \multicolumn{2}{c}{ FM mimoso } & \multicolumn{2}{c}{ FM BR451 } & \multicolumn{2}{c}{ FM BR2121 } \\
\cline { 2 - 9 } & g & $\%$ & g & $\%$ & g & $\%$ & g & $\%$ \\
\hline Farinha de trigo & 500,40 & 53,82 & -- & -- & -- & -- & -- & -- \\
FM mimoso & -- & -- & 490,90 & 54,14 & -- & -- & -- & -- \\
FM BR451 & -- & -- & -- & -- & 494,10 & 54,29 & -- & -- \\
FM BR2121 & -- & -- & -- & -- & -- & -- & 493,60 & 54,27 \\
Açúcar & 281,10 & 30,22 & 245,47 & 27,06 & 245,47 & 26,97 & 245,47 & 26,98 \\
Margarina & 142,40 & 15,31 & 164,47 & 18,13 & 164,47 & 18,07 & 164,47 & 18,08 \\
Fermento em pó & 6,07 & 0,67 & 6,07 & 0,67 & 6,07 & 0,67 & 6,07 & 0,67 \\
Total sólidos & 929,97 & 100,0 & 906,91 & 100,0 & 910,11 & 100,0 & 909,61 & 100,0 \\
Água destilada ${ }^{1}$ & q.s.p. & & q.s.p. & & q.s.p. & & q.s.p. & \\
Rend. massa crua & 2276 & & 2064 & & 2062 & & 2092 & \\
Rend. Biscoito & 1853 & & 1581 & & 1503 & & 1640 & \\
\hline
\end{tabular}

1 - Quantidade de água suficiente a ser adicionada para o desenvolvimento da massa.

\subsection{1 - Avaliação sensorial}

Os resultados dos biscoitos submetidos ao teste de comparação múltipla e de ordenação encontram-se na Tabela 4. Na análise dos resultados obtidos na comparação com os biscoitos controle, pôde-se constatar que não houve variação quanto à textura (igual ao padrão, nenhuma diferença) e ao sabor (pior que o padrão, pequena diferença) entre os três tipos de biscoitos. Entretanto, quanto à aparência, os biscoitos contendo FM mimoso e FM BR451 foram considerados iguais (melhor que o padrão, moderada diferença), e este último foi, por sua vez, equiparado ao biscoito contendo FM BR2121 (melhor que o padrão, pequena diferença). Quanto à preferência, os provadores indicaram em primeiro lugar os biscoitos com FM mimoso e FM BR451, seguidos pelo contendo FM BR2121, que foi considerado igual ao de FM BR451.

\subsection{2 - Composição centesimal}

Na Tabela 5 estão registrados os resultados da composição centesimal dos biscoitos preparados com as FM mimoso, FM BR451 e FM BR2121 e do biscoito contendo apenas farinha de trigo (controle), expressos na base seca, para possibilitar a comparação entre os produtos. Além disto, são apresentados também os niveis percentuais das frações da fibra alimentar solúvel e insolúvel.

TABELA 4. Avaliação sensorial dos biscoitos

\begin{tabular}{lccc}
\hline \multirow{2}{*}{ Atributo } & \multicolumn{3}{c}{ Biscoito à base de $^{1}$} \\
\cline { 2 - 4 } & FM mimoso & FM BR451 & FM BR2121 \\
\hline Comparação múltipla & & & \\
Aparência & $7,48 \mathrm{a}$ & $6,62 \mathrm{ab}$ & $6,24 \mathrm{~b}$ \\
Textura & $5,81 \mathrm{a}$ & $5,71 \mathrm{a}$ & $5,43 \mathrm{a}$ \\
Sabor & $4,71 \mathrm{a}$ & $4,67 \mathrm{a}$ & $4,48 \mathrm{a}$ \\
Ordenação & & & \\
Avaliação & $47 \mathrm{a}$ & $35 \mathrm{ab}$ & $32 \mathrm{~b}$ \\
\hline
\end{tabular}

1 - Médias seguidas pela mesma letra, na respectiva linha, não apresentam diferenmúltipla $(\mathrm{n}=21)$, e pelos testes de Friedman e Campos na ordenação $(\mathrm{n}=19)$. 
TABELA 5. Composição centesimal dos biscoitos

\begin{tabular}{|c|c|c|c|c|}
\hline \multirow{2}{*}{$\begin{array}{c}\text { Nutrientes } \\
(\mathrm{g} / 100 \mathrm{~g} \text { matéria seca) }\end{array}$} & \multicolumn{4}{|c|}{ Biscoito à base de ${ }^{1}$} \\
\hline & Farinha trigo & FM mimoso & FM BR451 & FM BR2121 \\
\hline Proteína bruta $^{2}$ & $6,63 \mathrm{~b}$ & $10,83 a$ & $11,74 \mathrm{a}$ & $11,65 \mathrm{a}$ \\
\hline Lípides & $12,29 \mathrm{~b}$ & $15,88 \mathrm{a}$ & $15,42 \mathrm{a}$ & $15,22 \mathrm{a}$ \\
\hline Cinzas & $0,86 \mathrm{~b}$ & $1,26 \mathrm{a}$ & $1,30 \mathrm{a}$ & $1,26 \mathrm{a}$ \\
\hline Fibra alimentar total & $2,50 \mathrm{~b}$ & $2,55 b$ & $3,39 a b$ & $3,83 a$ \\
\hline Carboidratos $^{3}$ & $77,71 \mathrm{a}$ & $69,47 \mathrm{~b}$ & $68,15 b$ & $68,04 \mathrm{~b}$ \\
\hline Nitrogênio & $1,16 \mathrm{~b}$ & $1,73 \mathrm{a}$ & $1,88 \mathrm{a}$ & $1,86 \mathrm{a}$ \\
\hline Fibra alimentar solúvel & $1,23 \mathrm{~b}$ & $1,23 b$ & $2,03 \mathrm{~b}$ & $2,15 \mathrm{a}$ \\
\hline Fibra alimentar insolúvel & $1,28 \mathrm{~b}$ & $1,33 \mathrm{~b}$ & $1,36 \mathrm{~b}$ & $1,68 \mathrm{a}$ \\
\hline \multicolumn{5}{|c|}{$\begin{array}{l}1 \text { - Os teores de umidade dos biscoitos à base de farinha de trigo (controle), FM } \\
\text { mimoso, FM BR451 e FM BR2121 foram, respectivamente (g/100g) 3,53c; 5,46a; } \\
5,48 \text { a e 5,00b. Médias seguidas pela mesma letra, na respectiva linha, não apresen- } \\
\text { tam diferenças significativas entre si, a } 5 \% \text { de probabilidade, pelo teste de Tukey. } \\
2 \text { - Fatores de conversão de nitrogênio: farinha de trigo = 5,70; FM mimoso, FM } \\
\text { BR451 e FM BR2 } 121 \text { = } 6,25 \text {. } \\
3 \text { - Teores calculados por diferença. }\end{array}$} \\
\hline
\end{tabular}

Os teores de umidade dos biscoitos preparados com as diversas farinhas mistas (Tabela 5) foram mais elevados que aquele com a farinha de trigo, o que se explica pela própria composição das mesmas, embora tenham ocorrido diferenças entre os biscoitos à base de FM BR2121 e os demais.

Observou-se que a substituição da farinha de trigo por outras fontes protéicas contribuiu para elevar a concentração de nutrientes nos biscoitos. Houve um aumento no teor protéico de até 63\%. Desconsiderando-se a contribuição da margarina, os niveis de lípides aumentaram em até $29 \%$. Isto se deve também à substituição da farinha de trigo pelos fubás que, embora degerminados, apresentavam um teor residual de lípides próximo ao encontrado para a farinha de trigo (Tabela 1). Os percentuais de cinzas nos biscoitos preparados com as FM foram superiores ao teor médio do biscoito controle. Provavelmente, este aumento pôde ser atribuído à presença do SLP mineralizado na formulação das farinhas mistas. Quanto aos teores médios de fibra alimentar, constataram-se valores inferiores, mas iguais entre si, nos biscoitos controle e à base da FM mimoso, mas cerca de $43 \%$ superiores naqueles contendo as FM à base dos fubás dos cultivares BR. Estas diferenças poderiam ser atribuídas aos diferentes métodos de degerminação e moagem. O parâmetro carboidratos representa uma fração de constituintes polissacarídeos não determinada por análise química nos produtos, sendo então obtida por diferença. Assim, verificou-se que o teor de carboidratos total é maior nos biscoitos à base de farinha de trigo, pois nas farinhas mistas houve substituição parcial da farinha de trigo por outras fontes protéicas, como os fubás mimoso, BR451 e BR2121, o IPS e o SLP, havendo diluição dos constituintes não determinados, além do efeito dos diferentes teores de umidade.

\subsection{3 - Qualidade nutricional}

- Valor calórico

O valor calórico é um parâmetro que envolve os teores de proteínas, carboidratos e lípides, ao mesmo tempo, sendo de interesse para efeito de rotulagem do produto e controle de calorias ingeridas. Os valores calóricos (kcal/100 g) dos biscoitos finais não foram diferentes entre eles, a saber: 432, à base de farinha trigo; 439, de FM mimoso; 438, de FM BR451 e 433, de FM BR2121.

\section{- Valor protéico em potencial}

A substituição parcial da farinha de trigo pela associação de fontes protéicas, tanto de origem animal (SLP) como vegetal (IPS e fubás mimoso, BR451 ou BR2 121) melhorou a qualidade protéica das FM e, conseqüentemente, dos biscoitos - expressa pela composição em aminoácidos essenciais e respectivos escores químicos, conforme apresentado na Tabela 6. Cumpre ressaltar que, ao se avaliarem os escores químicos dos biscoitos propriamente ditos, preparados com as diversas FM, não houve alterações nos respectivos valores. Isto porque a farinha mista era a única fonte protéica na formulação dos biscoitos, não ocorrendo variação nos teores dos aminoácidos essenciais, quando expressos em $\mathrm{mg} / \mathrm{g} \mathrm{N}$ das farinhas ou dos biscoitos.

Quando se comparou o escore químico do biscoito de farinha de trigo pura com os daqueles contendo as FM, verificou-se que de três aminoácidos deficientes lisina, treonina e triptofano, somente lisina continuou sendo limitante. Como os escores químicos dos biscoitos com os fubás QPM foram apenas 5\% superiores ao daquele com fubá mimoso, pôde-se concluir que as proteínas finais, contidas nos biscoitos produzidos com as FM mimoso, FM BR451 e FM BR2121 são caracterizadas pelos mesmos escores químicos.

TABELA 6. Escores químicos dos biscoitos

\begin{tabular}{|c|c|c|c|c|c|c|c|c|c|}
\hline \multirow{3}{*}{$\begin{array}{l}\text { Aminoácido } \\
\text { essencial }\end{array}$} & \multirow{3}{*}{$\begin{array}{c}\text { Referência' } \\
\mathrm{mg} / \mathrm{g} \mathrm{N}\end{array}$} & \multicolumn{8}{|c|}{ Biscoito à base de } \\
\hline & & \multicolumn{2}{|c|}{ Far. trigo ${ }^{2}$} & \multicolumn{2}{|c|}{ FM mimoso } & \multicolumn{2}{|c|}{ FM BR451 } & \multicolumn{2}{|c|}{ FM BR2121 } \\
\hline & & $\mathrm{mg} / \mathrm{g} \mathrm{N}$ & EQ & $\mathrm{mg} / \mathrm{g} \mathrm{N}$ & $E Q$ & $\mathrm{mg} / \mathrm{g} \mathrm{N}$ & EQ & $\mathrm{mg} / \mathrm{g} \mathrm{N}$ & $E Q$ \\
\hline Ile & 175 & 228 & 1,30 & 268 & 1,53 & 267 & 1,53 & 267 & 1,53 \\
\hline Leu & 413 & 440 & 1,07 & 508 & 1,23 & 484 & 1,17 & 484 & 1,17 \\
\hline Lis & 363 & 130 & 0,36 & 275 & 0,76 & 290 & 0,80 & 290 & 0,80 \\
\hline $\mathrm{Met} / \mathrm{Cis}$ & 156 & 250 & 1,60 & 218 & 1,40 & 226 & 1,45 & 226 & 1,45 \\
\hline $\mathrm{Fen} / \mathrm{Tir}$ & 394 & 449 & 1,14 & 508 & 1,29 & 490 & 1,24 & 490 & 1,24 \\
\hline Tre & 213 & 169 & 0,80 & 228 & 1,07 & 231 & 1,09 & 232 & 1,09 \\
\hline Tri & 69 & 67 & 0,98 & 82 & 1,18 & 82 & 1,19 & 82 & 1,19 \\
\hline Val & 219 & 258 & 1,18 & 299 & 1,37 & 305 & 1,39 & 305 & 1,39 \\
\hline
\end{tabular}

1 - Fonte: HENLEY \& KUSTER [17].

2 - Fonte: FAO [15]. EQ = escore químico.

Avaliar o valor nutritivo em potencial da proteína contida nestes biscoitos por métodos in vitro tem a vantagem de ser mais rápido e com custos reduzidos [2, 21]. Com base nos teores de aminoácidos essenciais e nas digestibilidades reais estabelecidas por ensaios biológico ou in vitro, constantes na literatura [17, 19, 26, 29] foi possivel calcular os indices: PDCAAS e C-PER - que já incluem a correção pela digestibilidade - dos biscoitos contendo as FM e compará-los aos do controle, contendo apenas farinha de trigo. Os resultados são apresentados na Tabela 7.

a - PDCAAS - constatou-se que grande parte dos aminoácidos essenciais do biscoito com farinha de trigo estava deficiente, sendo lisina o primeiro limitante $(0,29)$, seguida pela treonina $(0,64)$. Os biscoitos preparados com as FM também apresentaram deficiência nestes dois aminoácidos, porém em me- 
nor grau, cerca de $100 \%(0,59$ e 0,62$)$ e $31 \%(0,84$ e $0,85)$ superiores para a lisina e a treonina, respectivamente. Mesmo levando-se em consideração a digestibilidade e o fato de que o biscoito não constituirá a única fonte protéica na alimentação de um indivíduo, pôde-se afirmar que o emprego de FM com maior teor de proteína que o da farinha de trigo na elaboração de biscoitos, incrementou substancialmente o valor protéico em potencial do produto. A substituição do fubá de milho mimoso pelo do QPM degerminado, melhorou o PDCAAS em 5\%, como já constatado no escore químico.

b - C-PER - foi o índice teórico utilizado para estimar o nível de eficiência das proteínas dos biscoitos preparados com as farinha de trigo e mistas. Os valores encontrados para os biscoitos contendo as FM foram cerca de 2 unidades de PER superiores $(2,07$ e 2,13$)$ ao do controle $(0,77)$, e cerca de 0,4 unidades de PER inferiores ao da caseína, considerada como proteína padrão. Isto significa que, apesar de limitantes em alguns aminoácidos essenciais, a proteína contida nos produtos pode apresentar eficiência protéica, em relação ao ganho em peso. Cumpre ressaltar que a substituição parcial da farinha de trigo por $20 \%$ de fubá mimoso acarretou a complementação de aminoácidos entre o trigo e o milho, com melhoria no PER $(1,22)$ da mistura em relação ao da farinha de trigo $(0,83)$ e do fubá mimoso $(0,50)$, isoladamente [11]. Observou-se que os C-PER das FM foram superiores ao da mistura trigo:milho. As digestibilidades in vivo foram iguais a $95 \%$ para a farinha de trigo e $97 \%$ para a mistura trigo:milho, valores superiores aos aqui empregados, visto que estas fontes protéicas não passaram por um processamento, que costuma reduzir o valor do PER. Entretanto, em ensaio biológico com ratos, o PER para o milho Opaco-2 foi igual a 2,23 [20] e o do concentrado protéico de soja (70\% de proteína) igual a 2,00 [22] - valores estes próximos aos calculados para os biscoitos preparados com as FM contendo os fubás QPM e o IPS.

TABELA 7. Valor protéico em potencial dos biscoitos

\begin{tabular}{|c|c|c|c|}
\hline \multirow{2}{*}{$\begin{array}{c}\text { Índice } \\
\text { nutricional }^{1}\end{array}$} & \multicolumn{3}{|c|}{ Biscoito à base de } \\
\hline & Farinha trigo & FM mimoso & FM BR \\
\hline \multicolumn{4}{|l|}{ PDCAAS } \\
\hline \multirow[t]{6}{*}{ Aminoácido limitante } & Lis 0,29 & Lis 0,59 & Lis 0,62 \\
\hline & Tre 0,64 & Tre 0,84 & Tre 0,85 \\
\hline & Tri 0,78 & Tri 0,93 & Leu 0,92 \\
\hline & Leu 0,85 & Leu 0,96 & Tri 0,93 \\
\hline & AA ar 0,91 & & \\
\hline & Val 0,94 & & \\
\hline \multicolumn{4}{|l|}{ Caseína = AA s 0,56 } \\
\hline \multicolumn{4}{|l|}{ C-PER } \\
\hline & 0,77 & 2,07 & 2,13 \\
\hline Caseína = 2,51 & & & \\
\hline
\end{tabular}

1 - Corrigido para a digestibilidade: caseína $=90,03 \%$; farinha de trigo $=80 \%$, 1 - Corrigido para a digestibilidade: caseína $=90,03 \%$; farinha de trigo $=80 \%$,
farinhas mistas $=78 \%$. AA ar = aminoácidos aromáticos; AA s = aminoácidos farinhas mistarados.
sulfuratis

\subsection{4 - Custo dos produtos finais}

Apuração do custo de um produto novo é importante tendo em vista que um dos objetivos de se substituir parcialmente a farinha de trigo ao se preparar uma FM destinada à produção de biscoitos é reduzir o custo com a sua aquisição. A matéria-prima é importada (80\%) de outros países, estando o preço sujeito às variações cambiais. O custo final das misturas deveria ser igual ou inferior ao preço final da farinha de trigo pura, além de apresentar valor nutricional pelo menos igual [14].

Os preços $/ \mathrm{kg}$ relativos a todas as matérias-primas empregadas na produção dos biscoitos foram levantados no período de 28 a 31 de outubro de 2002. Considerou-se o custo do fubá de QPM igual ao do fubá mimoso, conforme apresentado a seguir

$\begin{array}{lrrlrr}\text { Farinha de trigo } & \mathrm{R} \$ & 1,46 & \text { Farinha mista } & \mathrm{R} \$ & 2,72 \\ \text { Fubá } & \mathrm{R} \$ & 0,89 & \text { Açúcar } & \mathrm{R} \$ & 1,14 \\ \text { Isolado protéico soja } & \mathrm{R} \$ & 15,00 & \text { Margarina } & \mathrm{R} \$ & 2,44 \\ \text { Soro leite em pó } & \mathrm{R} \$ & 2,60 & \text { Fermento em pó } & \mathrm{R} \$ & 19,80\end{array}$

É fácil constatar que a inclusão do IPS na FM, embora em percentual baixo, contribuiu para elevar em $55 \%$ o custo total da mesma. Com base nas diversas formulações, pôde-se estimar o custo da produção $/ \mathrm{kg}$ acrescido dos percentuais [31] relativos ao

- custo operacional médio - $133 \%$, para cobrir as despesas com recursos humanos, energia elétrica, água, empacotamento e eventuais, além da margem de lucro;

- custo médio devido a perdas - $10 \%$ sobre os custos anteriores, correspondente às perdas ocorridas durante o empacotamento e ou comercialização.

Na Tabela 8 são apresentados os resultados da avaliação feita.

TABELA 8 - Custo médio dos biscoitos contendo farinhas de trigo e mistas

\begin{tabular}{lcccc}
\hline \multirow{2}{*}{ Tipo de custo } & \multicolumn{4}{c}{ Biscoito assado à base de } \\
\cline { 2 - 5 } & Farinha trigo & FM mimoso & FM BR451 & FM BR2121 \\
\hline Ingredientes & 0,82 & 1,34 & 1,43 & 1,30 \\
Operacional $^{1}$ & 2,73 & 3,12 & 3,33 & 3,03 \\
Perdas $^{2}$ & 0,36 & 0,45 & 0,48 & 0,43 \\
Total em RS $^{*}$ & 3,91 & 4,91 & 5,24 & 4,76 \\
Total em US\$ $^{3}$ & 1.12 & 1.40 & 1.50 & 1.36 \\
\hline
\end{tabular}

1 - Refere-se às despesas com recursos humanos, energia elétrica, água, empacotamento e eventuais, além da margem de lucro (133\%).

2 - Refere-se às perdas ocorridas durante o empacotamento e ou comercialização $(10 \%)$.

3 - Considerou-se US\$1,00 = R\$3,50, para conversão $(04 / 11 / 02)$.

Observou-se pelos dados apresentados que nos biscoitos em que se utilizou as farinhas mistas, o custo foi superior ao preparado com farinha de trigo pura devido à necessidade de se empregar maiores quantidades dos ingredientes para se obter $1 \mathrm{~kg}$ do produto assado. Cumpre ressaltar que as quantidades de FM empregadas foram correlacionadas aos respectivos teores de umidade. Conseqüentemente, as quantidades 
dos outros ingredientes também aumentaram, sendo o custo mais elevado foi o do biscoito com FM BR451 (34\%). Considerou-se que, apesar das variações constatadas, se atingiu os objetivos propostos - mesmo com o custo mais elevado das FM - pois os produtos finais apresentaram qualidade protéica melhor.

\section{4 - CONCLUSÕES}

De modo geral, os resultados obtidos para os biscoitos contendo as farinhas mistas foram considerados satisfatórios quando comparados aos do biscoito contendo apenas farinha de trigo.

O emprego de fubá QPM na farinha mista acarretou pequena melhoria na qualidade nutricional, quando comparada com a do fubá mimoso.

Durante o desenvolvimento das formulações, uma ou outra apresentou escore químico superior aos das escolhidas, mas os biscoitos não foram bem aceitos pelos provadores.

\section{5 - REFERÊNCIAS BIBLIOGRÁFICAS}

[1] AMERICAN ASSOCIATION OF CEREAL CHEMIST AACC. Approved methods of the American Association of Cereal Chemist. 7. ed. Saint Paul: AACC, 1995. [s.p.] (Métodos 10-50 D, 54-10, 54-21).

[2] ANDERSON, R.H. Protein quality testing: industry needs. Food Technol., v. 32, n. 12, p. 65, 68, 1978.

[3] ASP, N.-G.; JOHANSSON, C.G.; HALLMER, H.; SILJESTRÖM, M. Rapid enzymatic assay of insoluble and soluble dietary fiber. J. Agric. Food Chem., v. 31, p. 476-482, 1983.

[4] ASSOCIATION OF OFFICIAL ANALYTICAL CHEMISTS AOAC. Official methods of analysis. 16. ed. Washington, DC: AOAC, 1995. v. 2. [s.p.] (Métodos 32.1.03, 32.1.05, 32.1.13, 32.1.22).

[5] CAMPOS, H. Estatística exeperimental nãoparamétrica. 2. ed. Piracicaba: Escola Superior de Agricultura "Luiz de Queiroz", 1976, 332 p. apud SHIROSI, I.; MORI, E.E.M. Estatística aplicada à análise sensorial. Campinas: Núcleo Especializado de Informação Tecnológica em Alimentos, 1994. mód. 1, 73 p. (Manual técnico, 13).

[6] CHAVES, J.B.P. Métodos de diferença em avaliação sensorial de alimentos e bebidas. Viçosa: 1993. 90 p.

[7] COMISSÃO NACIONAL DE NORMAS E PADRÕES PARA ALIMENTOS - CNNPA. Resolução 12/78 - Alimentos e bebidas: 47 padrões de identidade e qualidade. In: Associação Brasileira das Indústrias de Alimentação). Compêndio de resoluções da CNNPA. São Paulo; ABIA, 1978. $281 \mathrm{p}$.

[8] DIEMAIR, W. Laboratoriumsbuch für den Lebensmittelchemiker. 8. ed. Dresden: Theodor Steinkopff, 1963. p. 28-29, 38-39.

[9] DRUMMOND, A.L. Pão Forte/FSDT e pão francês: análise comparativa da composição centesimal e do valor nutritivo protéico em potencial. Belo Horizonte. 1996. 88 p. (Dissertação, Mestrado em Ciência de Alimentos). Faculdade de Farmácia da Universidade Federal de Minas Gerais.
[10] EL-DASH, A.; CABRAL, L.C.; GERMANI, R. Uso de farinha mista de trigo e soja na produção de pães. Brasília: Empresa Brasileira de Pesquisa Agropecuária, 1994. 89 p. (Coleção Tecnologia de farinhas mistas, v.3).

[11] EL-DASH, A.; GERMANI, R. Uso de farinha mista de trigo e milho na produção de pães. Brasília: Empresa Brasileira de Pesquisa Agropecuária, 1994a. 81 p. (Coleção Tecnologia de farinhas mistas, v. 2).

[12] EL-DASH, A.; GERMANI, R. Uso de farinha mista na produção de biscoitos. Brasília: Empresa Brasileira de Pesquisa Agropecuária, 1994b. 47 p. (Coleção Tecnologia de farinhas mistas, v. 6).

[13] ENDEF - Estudo nacional de despesa familiar. Tabela de composição dos alimentos. Rio de Janeiro: Instituto Brasileiro de Geografia e Estatística, 1977. 201 p.

[14] FIGUEIREDO, N.M.S.; CAMPOS, S.D.S.; VITTI, P.; TRAVAGLINI, M.M.E.; CIAMPI, C.M.S. Estudo técnico-econômico da obtenção de farinhas mistas para uso em panificação. Campinas: Instituto de Tecnologia de Alimentos, 1978. 64 p.

[15] FOOD AND AGRICULTURE ORGANIZATION - FAO. Amino acid content of foods and biological data of proteins. Rome: FAO, 1970. 285 p.

[16] GLASS, L.; HENDRICK, T.I. Nutritional composition of sweet and acid-type dry wheys. I Major factors including amino acids. J. Dairy Sci., v. 60, n. 2, p. 185-189, 1977.

[17] HENLEY, E.C.; KUSTER, J.M. Protein quality evaluation by digestibility-corrected amino acid scoring. Food Technol., v. 48, n. 4, p. 74-77, 1994.

[18] HSU, H.W.; SUTTON, N.E.; BANJO, M.O.; SATTERLEE, L.D.; HENDRICK, J.G. The C-PER and T-PER assays for protein quality. Food Technol., v. 32, n. 12, p. 6873, 1978.

[19] HSU, H.W.; VAVAK, D.L.; SATTERLEE, L.D.; MILLER, G.A. A multienzyme technique for estimating protein digestibility. J. Food Sci., v. 42, n. 5, p. 1269-1277, 1977.

[20] JOKL, L. Valor nutritivo de produtos obtidos da cultura do Saccharomyces cerevisiae em substrato de milho. Belo Horizonte. 1973. 91 p. (Dissertação, Mestrado em Bioquímica). Instituto de Ciências Biológicas - Universidade Federal de Minas Gerais.

[21] KENNEDY, J.F.; NOY, R.J.; STEAD, J.A.; WHITE, C.A. A new rapid enzyme digestion method for predicting in vitro protein quality (PDD index). Food Chem., v. 32, p. 277-295, 1989.

[22] LANGARO, A.; SCHIRMER, A.C.; MARCINKOWSKI, E.A. Avaliação de indices nutricionais de proteína de origem animal e vegetal em ratos Wistar em crescimento. In: CONGRESSO BRASILEIRO DE CIENCIA E TECNOlOGiA DE Alimentos, 16, 2002, Porto Alegre. Anais... Porto Alegre, SBCTA-Regional, 2002, p. 24012404 (CD-Rom).

[23] MIZUBUTI, I.Y. Soro de leite: composição, processamento e utilização na alimentação. Semina Ciênc. Agr., v. 15, p. 80-94, 1994.

[24] OSBORNE, D.R.; VOOGT, P. The analysis of nutrient in foods. London: Academic Press, 1978. p. 47, 156158.

[25] PEIXOTO, M.J.V.V.D.; PARENTONI, S.N.; GAMA, E.E.G.; MAGNAVACA, R.; PAIVA, E.; REGO, M.M. Perspectiva de utilização de milho de alta qualidade protéica no Brasil. Inf. Agropec., v. 14, n. 165, p. 2334, 1990. 
[26] PELLETT, P.L.; YOUNG, V.R. Nutritional evaluation of protein foods. Tokyo: The United Nations University, 1980. $154 \mathrm{p}$.

[27] PEREIRA, L.; CAMPOS, S.D.S. Produtos à base de soja em programas institucionais. Bol. Soc. Bras. Ciên. Tecnol. Alim., v. 16, p. 147-174, 1981.

[28] PIMENTEL-GOMES, F. Curso de estatística experimental. 13. ed. Piracicaba: Nobel. 1990. 468 p.

[29] SHEFFNER, A.L. In vitro protein evaluation. In: ALBANESE, A.A. (Ed.) Newer methods of nutritional biochemistry. New York: Academic Press, 1967. v. 3, p. 125-195.

[30] SHIROSI, I.; MORI, E.E.M. Estatística aplicada à análise sensorial. Campinas: Núcleo Especializado de
Informação Tecnológica em Alimentos, 1994. mód. 1, 73 p. (Manual técnico, 13).

[31] SOUZA, M.L.; RODRIGUES, R.S.; FURQUIM, M.F.G.; EL-DASH, A.A. Processamento de cookies de castanhado-brasil. Bol. Centro Pesq. Proces. Alim., v. 19, n. 2, p. 381-390, 2001.

\section{6 - AGRADECIMENTOS}

As autoras agradecem às empresas EMBRAPA/ CNPMS, Indústria Pink Ltda., Itambé Cooperativa Central de Produtores Rurais de Minas Gerais Ltda. e Vilma Alimentos pela doação de alguns ingredientes; à CAPES e ao CNPq pelo auxílio financeiro e bolsas concedidas. 